\title{
Research Paper: Investigating Syntax Comprehension in Persian-speaking Children With Autism
}

\author{
Hourieh Ahadi ${ }^{\text {* }}$ (1) \\ 1. Faculty of Linguistics, Institute for Humanities and Cultural Studies, Tehran, Iran.
}

\begin{tabular}{|c|c|}
\hline $\begin{array}{l}\text { Use your device toscan } \\
\text { and read the article online }\end{array}$ & \\
\hline 回虾古 & $\begin{array}{l}\text { ditation: Ahadi H. Investigating Syntax Comprehension in Persian-Speaking Children With Autism. Iranian Rehabilitation } \\
\text { Journal. 2019; 17(3):187-196. http://dx.doi.org/10.32598/irj.17.3.187 }\end{array}$ \\
\hline 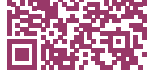 & doij http://dx.doi.org/10.32598/irj.17.3.187 \\
\hline
\end{tabular}

\section{(i) (3)}

Article info:

Received: 10 Jan 2019

Accepted: 23 May 2019

Available Online: 01 Sep 2019

Keywords:

Autistic disorder, Child, Language, Comprehension

\section{ABSTRACT}

Objectives: Grammar is frequently considered as the strength in the language profile of autistic children. Only a few studies have investigated the grammatical knowledge of these children. There are some research studies, but they are inconclusive, and less is known about the linguistic characteristics of children with autism in some languages, like Persian. Thus, the present study aimed at the detailed examining of syntax comprehension in Persian speaking children.

Methods: The required data were collected from 10 children with autism (6-9 years old) and 20 healthy children (10 age-matched and 10 language-matched). Then, we used the Gilliam Autism Rating Scale (GARS-2) for diagnosing autistic children. We used syntax comprehension test for assessing syntactic structures in children with autism and their normal peers. The obtained data were analyzed by statistical tests.

Results: The obtained results suggested a significant difference between the autistic group and age-matched healthy group in all structures, except for two elements, negative, an irreversible three-element sentence, reversible above and below, as well as sentences with object and subject pronoun. However, a comparison between the autistic group and the language-matched group revealed no significant difference in most structures, except for reversible passive, relative clause in the subject, relative clause in the object, and singular/ plural infection.

Discussion: Overall, autistic children have consistent comprehension impairment in relative clauses, reversible sentences, and morphosyntax, which should be seriously treated. The comparison of children with autism with age-matched healthy children indicated that a syntax comprehension test could be useful for differentiating Persian speaking children with autism from those with simple language delays.

\section{* Corresponding Author:}




\section{Highlights}

- There are significant differences in the total test scores between children with autism and healthy ones.

- Children with autism have consistent comprehension impairment in the relative clauses.

- They have impairment in reversible sentences and morphosyntax.

- Their syntax comprehension should be treated seriously.

- Their syntactic development is deviant.

\section{Plain Language Summary}

One of the characteristics of children with autism is their difficulties in communication and language use. We assessed whether autistic children's comprehension of language, especially syntax is similar to or deviant from their healthy counterparts. Furthermore, we explored the impaired structures in language comprehension in autistic children. This study suggested that children with autism have serious problems in language development; i.e. different from simple delays. Moreover, they have consistent comprehension impairment in some sentence types, which requires serious treatment.

\section{Introduction}

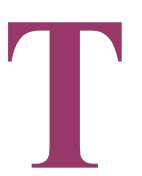

hree groups of developmental disorders are classified under Autism Spectrum Disorder (ASD), as follows: Autistic disorder (autism), Pervasive Developmental DisorderNot Otherwise Specified (PDD-NOS), and Asperger Syndrome (AS). Language acquisition deficit is one of the key diagnostic criteria of ASDs [1].

According to the Diagnostic and Statistical Manual (DSM-IV) of mental disorders-fourth edition criteria, the autistic disorder is characterized by difficulties in three areas; communication, social interaction, and restricted/ repetitive behaviors and interests. The onset of symptoms is before three years of age [1].

The prevalence of ASD is approximately 60 per 10000 births. Because of improvement in identification, categorization, and available services, the number of autistic children has increased [2]. Autism is a relatively rare developmental disorder; however, it is currently more prevalent than in the past.

Language acquisition in autistic children has been primarily studied in English speaking children, and fewer investigations have been conducted in other languages. However, cross-linguistic research in autism is necessary because it can help to reveal the nature of language acquisition in this population [3]. Importantly, some researchers believe that cross-linguistic autism studies can help create appropriate clinical tools for measuring language skills in this population within and across different cultures.

Grammar is frequently considered as the strength in the language profile of autistic children; however, few studies have investigated the grammatical knowledge of these children. The present study investigated the comprehension of syntax in Persian speaking children with autism. We specifically explored whether the comprehension of different structures is impaired or intact in autistic children, compared to healthy ones (language- and age-matched). Furthermore, we examined whether the autistic children's comprehension of syntax is similar to or different from their healthy counterparts. Moreover, we investigated the impaired/ intact structures in language comprehension in autistic children.

Data on the grammatical abilities of young autistic children are controversial (Table 1). Prior and Hall [4] found that children with ASD had deficits in the comprehension of reversible sentences, in comparison to mentally age-matched and healthy children.

Chan et al. investigated the language deficits of children with autism [5]. They analyzed the verbal expressioncomprehension abilities of 46 Chinese children aged 5-6 years. They used nonverbal intelligence to classify them into high- or low-functioning groups. They found that $(63 \%)$ of children with autism had language impair- 
ments. Notably, (42\%) had impairment in both verbal expression and comprehension abilities, and (21\%) had impairments only in expression skills [5].

Åsberg examined the patterns of language and discourse comprehension skills in Swedish school-aged children with autism $(n=16)$, compared to a younger group of healthy children $(n=16)$; they were matched for non-verbal cognitive ability. Children with autism indicated significant lower abilities in the comprehension of narrative discourse; however, they demonstrated no significant lower capabilities in the reception of grammar and vocabulary [6].

Noterdaeme and Wriedt studied the language function of children with AS and children with High-Functioning Autism (HFA) [7]. They used standardized tests and found that 10-year-old children with AS had better language skills than age-matched children with HFA; however, about $30 \%$ had problems in receptive language.

Eigsti and Marchena argued that children with autism have abnormal syntactic development [8]. They also found that conclusions are relevant to differences in autism diagnosis. Kjellmer and Hedvall analyzed the comprehension of language in children with ASD with normal Intelligence Quotient (IQ) [9]. They investigated the relationship between language comprehension and performance and found a delay in language comprehension development. The subgroup of children with autism was at the lower boundary of the normal range.

Kover and McDuffie characterized receptive vocabulary profiles in boys with ASD using cross-sectional developmental trajectories relative to age, nonverbal cognition, and expressive vocabulary [10]. They assessed receptive vocabulary with the Peabody picture vocabulary test and expressive vocabulary with the expressive vocabulary test. They found that receptive vocabulary increased at a lower rate in boys with ASD.

Kover and Haebig used a syntactic comprehension test and stated no significant difference in performance between autistic and healthy children who have the same measurement on receptive vocabulary [11]. They indicated a difference in comprehension ability in different sentence types, including reversible versus nonreversible sentences in the autistic population. Autistic children have some lexical errors in reversible sentence comprehension, unlike nonreversible sentences.

Tovar and Fein assessed the comprehension of tense/ aspect morphology in autistic children. They concluded that these children seemed to be quicker in matching scenes for both morphemes [12]. Children with more words and better performance on language tests had a better comprehension of '-ing.' As a conclusion, their comprehension was correlated with their spontaneous speech production and language test scores.

Durrleman and Hippolyte assessed syntax in autism by evaluating the comprehension of subject and object relative clause in autistic adolescents and adults with normal IQ, and with or without a history of language delay. Autistic participants should have pointed to a character designated for relative clauses [13]. They varied in syntactic complexity. Their achieved scores suggested that the autistic group's performance in object relative clauses, regardless of the language development history, was significantly worse than the healthy age-matched subjects. Furthermore, the performance of adults with a history of language delay was worse in subject relatives, compared to those without language delay. This finding suggests that these two groups have inequivalent linguistic abilities.

There are conflicting findings of delay or deficit in the syntactic development of autistic children; however, most studies have reported a significant delay in the syntactic domain of language. The present study aimed to examine the syntax comprehension ability in Persianspeaking children with an official test and understand their syntactic characteristics. We also determined the study participants' delays or deviances in this regard.

\section{Methods}

The study data were collected from 10 children with autism (males, age: 6-9 years). They ranged in age from 72 to 108 months. They were recruited from exceptional primary schools in Tehran City, Iran. The inclusion criteria were having been diagnosed with autism (based on GARS test), being monolingual, being 6-9 years old, and lacking significant medical conditions (e.g. deafness, blindness, etc.) or other neurological disorders (e.g. epilepsy, cerebral palsy, etc.).

The GARS-2 is a revision of the Gilliam Autism Rating Scale. Teachers and clinicians use this instrument for identifying and diagnosing autism in 3-22-year-old individuals. It is used for estimating the severity of autism, too.

The children's understanding of structures was assessed using the syntax comprehension test. Twentyfour syntactic structures and 96 items were assessed by this test. The syntax comprehension test can be used by researchers and speech and language pathologists as a 
Table 1. Summary of prior research studies

\begin{tabular}{|c|c|c|c|c|}
\hline Author(s) (year) & Language Measure & Language & $\begin{array}{l}\text { Healthy Control } \\
\text { Group }\end{array}$ & Autism Group \\
\hline $\begin{array}{l}\text { Prior and Hall } \\
\text { (1979) [4] }\end{array}$ & $\begin{array}{l}\text { The comprehension of } \\
\text { reversible sentences }\end{array}$ & English & $\begin{array}{l}\text { Mentally } \\
\text { age-matched }\end{array}$ & $\begin{array}{l}\text { They have deficits in the comprehension of } \\
\text { reversible sentences. }\end{array}$ \\
\hline $\begin{array}{l}\text { Kover and McDuff- } \\
\text { ie (2013) [10] }\end{array}$ & $\begin{array}{l}\text { Peabody picture vo- } \\
\text { cabulary test, } \\
\text { expressive vocabulary } \\
\text { test }\end{array}$ & English & $\begin{array}{l}\text { Healthy children with } \\
\text { same school age }\end{array}$ & $\begin{array}{l}\text { Their receptive vocabulary increased at a } \\
\text { lower rate. }\end{array}$ \\
\hline $\begin{array}{l}\text { Kover and Haebig } \\
\text { (2014) [11] }\end{array}$ & $\begin{array}{l}\text { The syntactic compre- } \\
\text { hension test }\end{array}$ & English & $\begin{array}{l}\text { Younger typically de- } \\
\text { veloping with the same } \\
\text { measurement } \\
\text { on receptive vocabulary }\end{array}$ & $\begin{array}{l}\text { There is a difference in their comprehension } \\
\text { ability in different sentence types; reversible } \\
\text { versus nonreversible sentences. }\end{array}$ \\
\hline $\begin{array}{l}\text { Tovar and Fein } \\
\text { (2015)[12] }\end{array}$ & $\begin{array}{l}\text { The comprehension of } \\
\text { tense/ aspect morphol- } \\
\text { ogy }\end{array}$ & English & & $\begin{array}{l}\text { Their comprehension was correlated with } \\
\text { their spontaneous speech production and } \\
\text { scores of language tests. }\end{array}$ \\
\hline $\begin{array}{l}\text { Chan et al. (2005) } \\
\text { [5] }\end{array}$ & $\begin{array}{l}\text { Verbal Expression } \\
\text { Test for Verbal Compre- } \\
\text { hension }\end{array}$ & Chinese & $\begin{array}{l}\text { Chronological age- } \\
\text { matched }\end{array}$ & $\begin{array}{c}\text { A total of } 42 \% \text { of them were impaired in } \\
\text { both verbal expression and comprehension } \\
\text { abilities. }\end{array}$ \\
\hline Åsberg (2010) [6] & $\begin{array}{l}\text { Peabody Picture Vo- } \\
\text { cabulary Test } \\
\text { Syntactic Comprehen- } \\
\text { sion Test (TROG-2) }\end{array}$ & Swedish & $\begin{array}{l}\text { The slightly younger } \\
\text { group of TD }\end{array}$ & $\begin{array}{l}\text { Their narrative discourse comprehension was } \\
\text { significantly lower, but not in oral receptive } \\
\text { vocabulary or the reception of grammar. }\end{array}$ \\
\hline $\begin{array}{l}\text { Durrleman and } \\
\text { Hippolyte (2015) } \\
\text { [13] }\end{array}$ & $\begin{array}{c}\text { The comprehension of } \\
\text { subject and object rela- } \\
\text { tive clause }\end{array}$ & French & Age-matched & Their performance was worse than TD. \\
\hline
\end{tabular}

Iranian Rehabilitation Journa

valid and reliable tool for evaluating the syntactic features of 4- to 6-year-old children. It could also be applied to diagnose syntax comprehension disorders in children aged $(\geq 5.5)$ years. The content validity index of the syntactic comprehension test was equal to 0.81 . There were significant differences between healthy children and those with specific language impairments $(\mathrm{P}>0.01)$ as well as low correlations among syntactic structures. These findings provided evidence for the scale's construct validity. A significant correlation was observed between the test scores in two rounds $(\mathrm{r}=0.56)$. The internal consistency of the test was equal to 0.89 [14].

For selecting the normal language-matched group, TOLDP2 was used. This test is reliable and valid. Its average reliability varied between 0.91 and 0.96 . It accesses the actual performance of children in 6 language components. These specific components of language structure are in receptive and expressive dimensions.

This study aimed to assess syntax comprehension in Persian-speaking children with autism. Thus, we measured the comprehension syntax ability of autistic children and compared them with those of healthy children. First, we used GARS for the diagnosis; then, the syntax comprehension test was performed by a speech therapist to evaluate the subjects' receptive ability in syntax. Then, 10 age-matched and 10 language-matched healthy children were selected and com- pared with autistic children. Descriptive statistics and MannWhitney $\mathrm{U}$ test were used to analyze the obtained data.

\section{Results}

Table 2 presents the between-group comparison of general receptive scores. As per (Table 2), in children with autism, the total score of the correct task is significantly lower than their age-matched and language-matched peers $(\mathrm{P}<0.05)$; however, their total score of the correct structure is significantly lower than their age-matched counterparts. Therefore, there was no significant difference between the children with autism and their language-matched peers on the total score of the correct structure.

According to (Table 3), there were some structures that some children with autism had completely performed. These structure are negative, reversible three-element sentences, comparative adjective, relative clause in subject, 'neither, nor', post modified subject, the dependent of nominal group, sentences with object and subject pronoun, object omitted sentence, the aspect of verb, four-element sentences, dependent pronoun as an object, and singular/ plural infection. Additionally, there were some structures which no subject could ideally conduct, such as a relative clause in the subject, fourelement sentences, and singular/ plural infection. 
Table 2. Mann-Whitney $U$ test results of comparing general receptive scores

\begin{tabular}{ccc}
\hline Groups & Correct Structure & Correct Tasks \\
\hline Autism \& age-matched groups & 0.001 & 0.001 \\
\hline Autism \& language-matched groups & 0.379 & 0.020 \\
\hline
\end{tabular}

Iranian Rehabilitation Journal

Table 4 lists an analysis of variance between the autistic and age-matched group. Based on Mann-Whitney $\mathrm{U}$ test, there were significant differences $(\mathrm{P}<0.05)$ in all structures, except for two elements, negative, an irrevers- ible three-element sentence, sentences with the coordinate phrase, sentences with object and subject pronoun, dependent pronoun as an object, and singular/ plural infection.

Table 3. Descriptive statistics in the autistic group

\begin{tabular}{|c|c|c|c|}
\hline Type of Structure & Min. & Max. & Mean \pm SD \\
\hline Two elements & 3.00 & 4.00 & $3.7000 \pm 0.48305$ \\
\hline Negative & 0.00 & 4.00 & $2.9000 \pm 1.85293$ \\
\hline An irreversible three-element sentence & 3.00 & 4.00 & $3.6000 \pm 0.69921$ \\
\hline Coordinate phrases by 'also' & 1.00 & 4.00 & $2.9000 \pm 1.10050$ \\
\hline Superlative adjective & 1.00 & 4.00 & $2.9000 \pm 1.28668$ \\
\hline A reversible three-element sentence & 0.00 & 4.00 & $1.9000 \pm 1.52388$ \\
\hline Coordinate noun phrases by 'in' and 'on' & 2.00 & 4.00 & $2.8000 \pm 0.91894$ \\
\hline$X$ but not & 2.00 & 4.00 & $2.8000 \pm 0.78881$ \\
\hline Sentences with coordinate phrase & 2.00 & 4.00 & $3.8000 \pm 0.63246$ \\
\hline Reversible passive & 1.00 & 4.00 & $1.8000 \pm 0.91894$ \\
\hline Reversible above and below & 1.00 & 4.00 & $2.1000 \pm 1.28668$ \\
\hline Comparative adjective & 0.00 & 4.00 & $2.1000 \pm 1.59513$ \\
\hline Relative clause in subject & 0.00 & 3.00 & $2.1000 \pm 0.99443$ \\
\hline Pronoun binding & 1.00 & 4.00 & $2.4000 \pm 0.96609$ \\
\hline Relative clause in object & 1.00 & 4.00 & $2.1000 \pm 1.10050$ \\
\hline Neither, nor & 0.00 & 4.00 & $1.1000 \pm 1.44914$ \\
\hline Post modified subject & 0.00 & 4.00 & $2.1000 \pm 1.19722$ \\
\hline Dependent of nominal group & 0.00 & 4.00 & $1.7000 \pm 1.25167$ \\
\hline Sentences with object and subject pronoun & 0.00 & 4.00 & $2.0000 \pm 1.49071$ \\
\hline Object omitted sentence & 0.00 & 4.00 & $1.6000 \pm 1.17379$ \\
\hline The aspect of verb & 0.00 & 4.00 & $1.9000 \pm 1.10050$ \\
\hline Four-element sentences & 0.00 & 3.00 & $1.8000 \pm 1.13529$ \\
\hline Dependent pronoun as an object & 0.00 & 4.00 & $2.4000 \pm 1.34990$ \\
\hline Singular/plural infection & 0.00 & 3.00 & $1.9000 \pm 0.99443$ \\
\hline
\end{tabular}

Iranian Rehabilitation Journal 
Table 4. Mann-Whitney U test results of comparing receptive syntax in autistic and age-matched groups

\begin{tabular}{|c|c|c|c|c|}
\hline Type of Structure & $\mathbf{P}$ & $\mathbf{Z}$ & Wilcoxon Test & Mann-Whitney U Test \\
\hline Two elements & 0.150 & 1.441 & 76.000 & 21.000 \\
\hline Negative & 0.087 & 1.712 & 73.000 & 18.000 \\
\hline An irreversible three-element sentence & 0.151 & 1.434 & 76.000 & 21.000 \\
\hline Coordinate phrases by 'also' & 0.024 & 2.254 & 67.000 & 12.000 \\
\hline Superlative adjective & 0.047 & 1.982 & 70.000 & 15.000 \\
\hline A reversible three-elements sentence & 0.005 & 2.795 & 61.000 & 6.000 \\
\hline Coordinate noun phrases by 'in' and 'on' & 0.011 & 2.558 & 64.000 & 9.000 \\
\hline $\mathrm{X}$ but not & 0.005 & 2.828 & 61.000 & 6.000 \\
\hline Sentences with coordinate phrase & 0.777 & 0.283 & 49.500 & 28.500 \\
\hline Reversible passive & 0.002 & 3.133 & 58.000 & 3.000 \\
\hline Reversible above and below & 0.011 & 2.540 & 63.000 & 8.000 \\
\hline Comparative adjective & 0.012 & 2.517 & 64.000 & 9.000 \\
\hline Relative clause in subject & 0.002 & 3.155 & 57.000 & 2.000 \\
\hline Pronoun binding & 0.005 & 2.787 & 60.500 & 5.500 \\
\hline Relative clause in object & 0.002 & 3.140 & 57.000 & 2.000 \\
\hline Neither, nor & 0.003 & 2.946 & 59.000 & 4.000 \\
\hline Post modified subject & 0.024 & 2.262 & 64.500 & 9.500 \\
\hline The dependent of nominal group & 0.003 & 2.925 & 59.000 & 4.000 \\
\hline Sentences with object and subject pronoun & 0.375 & 0.887 & 77.000 & 22.000 \\
\hline Object omitted sentence & 0.005 & 2.806 & 60.000 & 5.000 \\
\hline The aspect of verb & 0.024 & 2.254 & 65.000 & 10.000 \\
\hline A four-element sentence & 0.004 & 2.874 & 59.500 & 4.500 \\
\hline Dependent pronoun as an object & 0.209 & 1.258 & 74.000 & 19.000 \\
\hline Singular/ plural infection & 0.315 & 1.005 & 76.000 & 21.000 \\
\hline
\end{tabular}

Iranian Rehabilitation Journal

Table 5 presents a comparison between autistic and language-matched healthy groups. There was no significant difference $(\mathrm{P}<0.05)$ in most structures, except for reversible passive, relative clause in the subject, a relative clause in the object, and singular/ plural infection.

\section{Discussion}

This was the first study to present detailed data on the comprehension of language in Persian speaking children with autism aged 6-9 years. The obtained results revealed that in correct task score, children with autism performed at a significantly lower level than their age-matched and language-matched peers; however, in correct structure scores, children with autism performed at a significantly lower level than their age-matched counterparts (Table 2). As each structure of the syntax measures a different syntactic skill, they were examined separately.

The pattern of performance across the different structures appeared to be more uneven for children with autism, compared to their language- and age-matched controls. A more accurate assessment of the individual data of children with autism, and exploring possible differences in performance are provided in (Table 2). In the descriptive statistics for the children with autism on this test, 0 indicates a failed structure, and 4 indicates a passed structure. There was wide variability in the total number of structures passed by each study participant with autism. 
Table 5. Mann-Whitney $U$ test results of comparing receptive syntax in autistic and language-matched groups

\begin{tabular}{|c|c|c|c|c|}
\hline Type of Structure & $\mathbf{P}$ & Z & Wilcoxon Test & $\begin{array}{c}\text { Mann-Whitney U } \\
\text { Test }\end{array}$ \\
\hline Two elements & 0.121 & 1.549 & 79.500 & 24.500 \\
\hline Negative & 0.066 & 1.838 & 76.000 & 21.000 \\
\hline An irreversible three-element sentence & 0.429 & 0.790 & 84.000 & 29.000 \\
\hline Coordinate phrases by 'also' & 0.350 & 0.934 & 81.000 & 26.000 \\
\hline Superlative adjective & 0.671 & 0.425 & 86.000 & 31.000 \\
\hline A reversible three-element sentence & 0.089 & 1.700 & 73.000 & 18.000 \\
\hline Coordinate noun phrases by 'in' and 'on' & 0.539 & 0.614 & 84.000 & 29.000 \\
\hline $\mathrm{X}$ but not & 0.092 & 1.683 & 74.000 & 19.000 \\
\hline Sentences with coordinate phrase & 0.168 & 1.380 & 52.500 & 24.500 \\
\hline Reversible passive & 0.023 & 2.272 & 67.500 & 12.500 \\
\hline Reversible above and bellow & 0.093 & 1.680 & 73.500 & 18.500 \\
\hline Comparative adjective & 0.249 & 1.152 & 78.500 & 23.500 \\
\hline Relative clause in subject & 0.028 & 2.196 & 49.000 & 14.000 \\
\hline Pronoun binding & 0.107 & 1.614 & 74.500 & 19.500 \\
\hline Relative clause in object & 0.009 & 2.600 & 64.000 & 9.000 \\
\hline Neither, nor & 0.158 & 1.411 & 76.000 & 21.000 \\
\hline Post modified subject & 0.612 & 0.507 & 85.000 & 30.000 \\
\hline The dependent of the nominal group & 0.064 & 1.836 & 72.000 & 17.000 \\
\hline Sentences with object and subject pronoun & 0.687 & 0.402 & 59.000 & 31.000 \\
\hline Object omitted sentence & 0.178 & 1.347 & 77.000 & 22.000 \\
\hline The aspect of verb & 0.183 & 1.331 & 77.500 & 22.500 \\
\hline A four-element sentence & 0.764 & 0.301 & 87.000 & 32.000 \\
\hline Dependent pronoun as an object & 0.582 & 0.550 & 57.500 & 29.500 \\
\hline Singular/plural infection & 0.033 & 2.133 & 42.000 & 14.000 \\
\hline
\end{tabular}

Iranian Rehabilitation Journal

Table 3 suggests that some children with autism had completely performed some structures $(\max =4)$, such as negative, reversible three-element sentences, comparative adjective, relative clause in subject, neither nor, post-modified subject, the dependent of nominal group, sentences with object and subject pronoun, object omitted sentence, the aspect of verb, four-element sentences, dependent pronoun as an object, and singular/ plural infection. Thus, these structures seem to be easier structures for children with autism, as some children can perform those perfectly. Moreover, there were some structures that none of the children with autism could correctly perform $(\max =0)$, such as relative clause in the subject, four-element sentences, and singular/ plural infection. These structures seem that should be treated seriously; because all of the children with autism have problems with them.

ANOVA results of autistic and age-matched healthy group in (Table 4) suggested significant differences in all structures, except for some structures, like two elements, negative, irreversible three-element sentences, sentences with coordinate phrase, sentences with object and subject pronoun, dependent pronoun as an object, and sin- 
gular/ plural infection $(\mathrm{P}<0.05)$. It seems that these are the simplest structures, and autistic children can perform them successfully. In (Table 5), the comparison between autistic and language-matched healthy groups revealed no significant differences in most structures, except for reversible passive $(\mathrm{P}=0.023)$, relative clause in the subject $(\mathrm{P}=0.028)$, relative clause in the object $(\mathrm{P}=0.009)$, and singular/ plural infection $(\mathrm{P}=0.033)$.

The achieved results revealed the delayed comprehension of syntax in children with autism, compared to healthy age- and language-matched children. These data are consistent with the results of Prior and Hall, Howlin, Tager-Flusberg and Calkins, Noterdaeme, Eigsti and Marchena, Kjellmer and Hedvall, Kover and McDuffie, and Kover and Haebig; however in contrast with the results of Asberg reported significant lower abilities in the comprehension of narrative discourse in the ASD group $[4-11,15,16]$. However, the group had no problem with understanding receptive vocabulary or grammar. Asberg compared children with autism with a younger group of healthy children matched for non-verbal cognitive ability; however, our comparison group was aged-matched.

Thus, the reason for these differences may be the difference in matching the control group. This finding also reveals that the result of language comparison in Persian is the same as the finding of English, French, and Chinese, but different from Swedish. This difference can also be due to differences in languages. Asberg recruited participants from different schools for children with ASD and other developmental disabilities as well as from a mainstream school. The entire participants had not received an ASD diagnosis. Eight of them had AD, one of them had an autism-like condition and one participant had an additional Attention Deficit Hyperactivity Disorder (ADHD) diagnosis. He assumed that this diversity affected his collected results.

Prior and Hall found that children with ASD had deficits in the comprehension of reversible sentences, in comparison to healthy, mentally age-matched peers [4]. Kover and McDuffie also indicated difficulties in the comprehension ability of reversible sentences; the children with ASD were more likely to have a lexical error in reversible sentence comprehension, compared to healthy boys [10]. We found that autistic children have a significant difference with their age-matched and languagematched counterparts in reversible three-element sentences, but not in irreversible three-element sentences. In conclusion, reversible sentence comprehension is very problematic for children with autism.
Durrleman and Hippolyte assessed syntax in autism by evaluating the comprehension of subject and object relative clause in autistic adolescents and adults with normal IQ, and with or without histories of language delay [13]. Their scores indicated that the performance of the autistic group in object relative clauses was significantly worse than that of the healthy age-matched group. In this study, the autistic group had language delay and demonstrated significant differences with their language-matched peers in subject and object relative. Thus, "relative clause" is another problematic structure, requiring treatment.

\section{Conclusion}

Few studies have examined the grammatical abilities of children with autism in detail, and some of them have contradictory findings. Howlin concluded that autistic children's syntactic development is delayed, but follows a normal trajectory concerning normally-developing children; while others concluded that syntax is deviant in a more fundamental way $[15,17]$. This study supports the results of Bartolucci, Pierce as we found that the result of the comprehension test between children with autism and their age-matched controls was significantly different [17]. We also found that autistic children have consistent comprehension impairment in relative clause, reversible sentences, and morphosyntax, which requires serious treatment.

\section{Ethical Considerations}

\section{Compliance with ethical guidelines}

All participants filled a consent form to confirm their voluntarily participation in the study.

\section{Funding}

This project was supported and founded with Institute for Humanities and Cultural science. (Research project Code: 444).

\section{Conflict of interest}

The author declared no conflict of interest.

\section{Acknowledgments}

The author thanks Institute for Humanities and Cultural science for financial support. 


\section{References}

[1] American Psychological Association. Diagnostic and statistical manual of mental disorders (DSM- $5 \AA$ ), $5^{\text {th }}$ edition. Philadelphia: American Psychiatric Association; 2013. [DOI:10.1176/appi.books.9780890425596]

[2] Akshoomoff N, Stahmer A. Early intervention programs and policies for children with autistic spectrum disorders. In: Fitzgerald HE, Lester BM, and Zuckerman B, editors. The Crisis in Youth Mental Health: Critical Issues and Effective Programs. Westport, Praeger; 2006.

[3] Luyster RJ, Kadlec MB, Carter A, Tager-Flusberg H. Language assessment and development in toddlers with autism spectrum disorders. Journal of Autism and Developmental Disorders. 2008; 38(8):1426-38. [DOI:10.1007/s10803-0070510-1] [PMID]

[4] Prior MR, Hall LC. Comprehension of transitive and intransitive phrases by autistic, retarded, and normal children. Journal of Communication Disorders. 1979; 12(2):103-11. [DOI:10.1016/0021-9924(79)90033-9]

[5] Chan AS, Cheung J, Leung WWM, Cheung R, Cheung M-C. Verbal expression and comprehension deficits in young children with autism. Focus on Autism and Other Developmental Disabilities. 2005; 20(2):117-24. [DOI:10.1177/10883576050 200020201]

[6] Åsberg J. Patterns of language and discourse comprehension skills in school-aged children with autism spectrum disorders. Journal of Psychology. 2010; 51(6):534-9. [DOI:10.1111/ j.1467-9450.2010.00822.x] [PMID]

[7] Noterdaeme M, Wriedt E, Höhne C. Asperger's syndrome and high-functioning autism: Language, motor and cognitive profiles. European Child and Adolescent Psychiatry. 2010; 19(6):475-81. [DOI:10.1007/s00787-009-0057-0] [PMID]

[8] Eigsti I-M, de Marchena AB, Schuha JM, Kelley E. Language acquisition in autism spectrum disorders: A developmental review. Research in Autism Spectrum Disorders. 2011 5(2):681-91. [DOI:10.1016/j.rasd.2010.09.001]

[9] Kjellmer L, Hedvall Å, Holm A, Fernell E, Gillberg G, Norrelgen $F$. Language comprehension in preschoolers with autism spectrum disorders without intellectual disability: Use of the Reynell Developmental Language Scales. Research in Autism Spectrum Disorders. 2012; 6(3):1119-25. [DOI:10.1016/j. rasd.2012.03.003]

[10] Kover ST, McDuffie AS, Hagerman RJ, Abbeduto L. Receptive vocabulary in boys with autism spectrum disorder: Cross-sectional developmental trajectories. Journal of $\mathrm{Au}$ tism and Developmental Disorders. 2013; 43(11):2696-709. [DOI:10.1007/s10803-013-1823-x] [PMID] [PMCID]

[11] Kover ST, Haebig E, Oakes A, McDuffie AS, Hagerman RJ, Abbeduto L. Sentence comprehension in boys with Autism spectrum disorder. American Journal of Speech-Language Pathology. 2014; 23(3):385-94. [DOI:10.1044/2014_ AJSLP-13-0073] [PMID] [PMCID]

[12] Tovar AT, Fein D, Naigles LR. Grammatical aspect is a strength in the language comprehension of young children with autism spectrum disorder. Journal of Speech, Language, and Hearing Research. 2015; 58:301-10. [DOI:10.1044/2014 JSLHR-L-13-0257] [PMID] [PMCID]
[13] Durrleman S, Hippolyte L, Zufferey S, Iglesias K, Hadjikhani N. Complex syntax in autism spectrum disorders: A study of relative clauses. International Journal of Language \& Communication Disorders. 2015; 50(2):260-7. [DOI:10.1111/14606984.12130] [PMID]

[14] Mohamadi R. Development and standardization of a syntax comprehension test for persian 4-6 year old children, in department of speech therapy. Tehran: University of Social Welfare and Rehabilitation Sciences; 2014.

[15] Howlin P. The acquisition of grammatical morphemes in autistic children: A critique and replication of the findings of Bartolucci, Pierce, and Streiner, 1980. Journal of Autism and Developmental Disorders. 1984; 14(2):127-36. [DOI:10.1007/ BF02409656] [PMID]

[16] Tager-Flusberg H, Calkins S. Does imitation facilitate acquisition of grammar? Evidence from the study of autistic, Down's syndrome and normal children. Journal of Child Language. 1990; 17(3):591-606. [DOI:10.1017/S0305000900010898] [PMID]

[17] Bartolucci G, Pierce SJ, Streiner D. Cross-sectional studies of grammatical morphemes in autistic and mentally retarded children. Journal of Autism and Developmental Disorders. 1980; 10(1):39-50. [DOI:10.1007/BF02408431] [PMID] 
This Page Intentionally Left Blank 